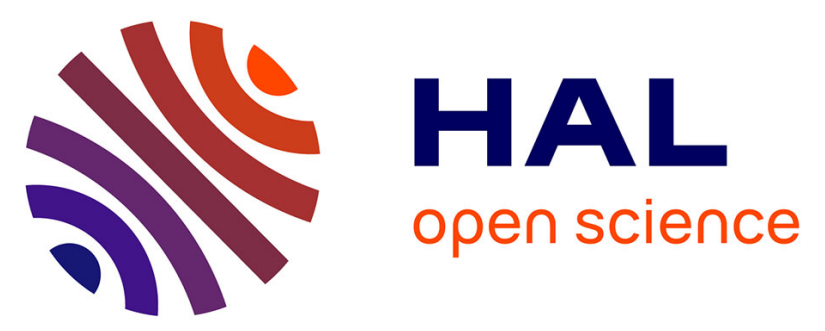

\title{
Formation of trans-epoxy fatty acids correlates with formation of isoprostanes and could serve as biomarker of oxidative stress
}

Katharina M Rund, Daniel Heylmann, Nina Seiwert, Sabine Wecklein, Camille Oger, Jean-Marie Galano, Thierry Durand, Rongjun Chen, Faikah Gueler, Jörg Fahrer, et al.

\section{To cite this version:}

Katharina M Rund, Daniel Heylmann, Nina Seiwert, Sabine Wecklein, Camille Oger, et al.. Formation of trans-epoxy fatty acids correlates with formation of isoprostanes and could serve as biomarker of oxidative stress. Prostaglandins and Other Lipid Mediators, 2019, 144, pp.106334. 10.1016/j.prostaglandins.2019.04.004 . hal-02417592

\section{HAL Id: hal-02417592 \\ https://hal.science/hal-02417592}

Submitted on 18 Dec 2019

HAL is a multi-disciplinary open access archive for the deposit and dissemination of scientific research documents, whether they are published or not. The documents may come from teaching and research institutions in France or abroad, or from public or private research centers.
L'archive ouverte pluridisciplinaire HAL, est destinée au dépôt et à la diffusion de documents scientifiques de niveau recherche, publiés ou non, émanant des établissements d'enseignement et de recherche français ou étrangers, des laboratoires publics ou privés. 


\title{
Formation of trans-epoxy fatty acids correlates with formation of isoprostanes and could serve as biomarker of oxidative stress
}

\author{
Katharina M. Rund ${ }^{\mathrm{a}, \mathrm{b}}$, Daniel Heylmann ${ }^{\mathrm{c}}$, Nina Seiwert ${ }^{\mathrm{c}}$, Sabine Wecklein ${ }^{\mathrm{d}}$, Camille Oger ${ }^{\mathrm{e}}$, \\ Jean-Marie Galano ${ }^{\mathrm{e}}$, Thierry Durand ${ }^{\mathrm{e}}$, Rongjun Chen $^{\mathrm{f}}$, Faikah Gueler ${ }^{\mathrm{f}}$, Jörg Fahrer ${ }^{\mathrm{c}, \mathrm{d}}$, \\ Julia Bornhorst $^{\mathrm{b}, \mathrm{g}}$, Nils Helge Schebb ${ }^{\mathrm{a}, \mathrm{b}, *}$ \\ ${ }^{a}$ Institute for Food Toxicology, University of Veterinary Medicine Hannover, Hannover, Germany \\ ${ }^{\mathrm{b}}$ Chair of Food Chemistry, Faculty of Mathematics and Natural Sciences, University of Wuppertal, Wuppertal, Germany \\ ${ }^{\mathrm{c}}$ Rudolf Buchheim Institute of Pharmacology, Justus Liebig University Giessen, Giessen, Germany \\ ${ }^{\mathrm{d}}$ Institute of Toxicology, University Medical Center Mainz, Mainz, Germany \\ ${ }^{\mathrm{e}}$ Institut des Biomolécules Max Mousseron (IBMM), UMR 5247 CNRS, Université de Montpellier, ENSCM, France \\ ${ }^{\mathrm{f}}$ Nephrology, Hannover Medical School, Hannover, Germany \\ ${ }^{\mathrm{g}}$ Institute of Nutritional Science, University of Potsdam, Nuthetal, Germany
}

A B S T R A C T

In mammals, epoxy-polyunsaturated fatty acids (epoxy-PUFA) are enzymatically formed from naturally occur-ring all-cis PUFA by cytochrome P450 monooxygenases leading to the generation of cis-epoxy-PUFA (mixture of $R, S$ - and $S, R$-enantiomers). In addition, also non-enzymatic chemical peroxidation gives rise to epoxy-PUFA leading to both, cis- and trans-epoxy-PUFA (mixture of $R, R$ - and $S, S$-enantiomers). Here, we investigated for the first time trans-epoxy-PUFA and the trans/cis-epoxy-PUFA ratio as potential new biomarker of lipid peroxidation. Their formation was analyzed in correlation with the formation of isoprostanes (IsoP), which are commonly used as biomarkers of oxidative stress. Five oxidative stress models were investigated including incubations of three human cell lines as well as the in vivo model Caenorhabditis elegans with tert-butyl hydroperoxide $(t-\mathrm{BOOH})$ and analysis of murine kidney tissue after renal ischemia reperfusion injury (IRI). A comprehensive set of IsoP and epoxy-PUFA derived from biologically relevant PUFA (ARA, EPA and DHA) was simultaneously quantified by LC-ESI(-)-MS/ MS. Following renal IRI only a moderate increase in the kidney levels of IsoP and no relevant change in the trans/cis-epoxy-PUFA ratio was observed. In all investigated cell lines (HCT-116, HepG2 and Caki-2) as well as C. elegans a dose dependent increase of both, IsoP and the trans/cis-epoxy-PUFA ratio in response to the applied $t$-BOOH was observed. The different cell lines showed a distinct time dependent pattern consistent for both classes of autoxidatively formed oxylipins. Clear and highly significant correlations of the trans/cis-epoxy-PUFA ratios with the IsoP levels were found in all investigated cell lines and C. elegans. Based on this, we suggest the trans/cis-epoxy-PUFA ratio as potential new biomarker of oxidative stress, which warrants further investigation.

Keywords:

Isoprostane

Trans-epoxy-fatty acid

Oxidative stress

Biomarker

Oxylipin

Eicosanoid

\section{Introduction}

Oxidative stress, i.e. the imbalance of antioxidative and oxidative mechanisms is associated with the pathophysiology of several diseases. It is characterized by an impairment of redox signaling and control in the organism, ambivalently caused and/or resulting by the disease state [1]. Various diseases are linked to oxidative stress including inflammatory, cardiovascular, respiratory and neurological diseases [2].

Elevated levels of reactive oxygen and nitrogen species formed in the course of oxidative stress oxidatively modify biomolecules including lipids, proteins, DNA, thereby altering their biological properties and function. Polyunsaturated fatty acids (PUFA) which are essential constituents in membrane phospholipids are susceptible to free radical mediated autoxidation [3]. During this lipid peroxidation radical abstraction of a bisallylic hydrogen and subsequent addition of molecular oxygen results initially in conversion of PUFA to hydroperoxy fatty acid radicals which are further converted in chain oxidation reactions giving rise to a multitude of reactive and stable secondary oxidation products which inter alia bear hydro(pero)xy-, epoxy- and cyclic moieties [4]. Several of these products arising during non-

\footnotetext{
* Corresponding author: Chair of Food Chemistry, Faculty of Mathematics and Natural Sciences, University of Wuppertal, Gaußstr. 20, 42119, Wuppertal, Germany. E-mail address: nils@schebb-web.de (N.H. Schebb).
} 
enzymatic autoxidation are structurally similar to products formed by enzymatic conversion. However, enzymatic conversion of PUFA by cyclooxygenase (COX) results in regio- and stereospecific formation of prostaglandins (PG) whereas non-enzymatic lipid peroxidation leads to a complex mixture of regio- and stereoisomeric prostaglandin-like products, referred to as isoprostanes (IsoP), comprising in the case of arachidonic acid (ARA, C20:4n6) 64 different $\mathrm{F}_{2}$-IsoP isomers [5,6]. While only free, i.e. non-esterified, PUFA are enzymatically converted by COX, IsoP are formed from PUFA esterified in phospholipids and are released upon stimuli [7]. PG, like $\mathrm{PGE}_{2}$, are known to be potent mediators of inflammation and for selected IsoP also biological activity has been shown, e.g. 15- $\mathrm{F}_{2 \mathrm{t}}$-IsoP acting as renal vasoconstrictor [8]. ARA derived $\mathrm{F}_{2}$-IsoP, especially $15-\mathrm{F}_{2 \mathrm{t}}$-IsoP $\left(8-i s o-\mathrm{PGF}_{2 \alpha}\right)$, were assessed to be valuable for the evaluation of oxidative stress in vivo and the latter is commonly used as biomarker in diseases and environmental exposures implicated with oxidative stress [9-11]. However, in recent years the validity of the sole measurement of $15-\mathrm{F}_{2 \mathrm{t}}$-IsoP as biomarker of oxidative stress is regarded controversial as it besides non-enzymatic autoxidation may also arise from enzymatic conversion by COX $[12,13]$. To account for the contribution of both pathways to the detected $15-\mathrm{F}_{2 \mathrm{t}}$-IsoP level, determination of the $15-\mathrm{F}_{2 \mathrm{t}}-\mathrm{IsoP} / \mathrm{PGF}_{2 \alpha}$ ratio may be used to differentiate between non-enzymatic and enzymatic formation and enable accurately evaluating the underlying oxidative stress $[14,15]$. Moreover, the parallel analysis of different IsoP isomers from individual as well as multiple biological relevant PUFA - as carried out in the present study - allows drawing comprehensive conclusions on the oxidative stress status independent from the origin of the analyzed specimen.

In addition to IsoP a multitude of autoxidative PUFA products is generated during lipid peroxidation. This includes products with epoxy moieties resulting from hydroperoxides by intramolecular homolytic substitution of the peroxide bond by an adjacent carbon radical [4]. Epoxy-PUFA are well characterized highly potent lipid mediators which possess important biological properties, e.g. acting anti-inflammatory and vasodilatory [16] and are present in body fluids and tissues (e.g. plasma, red blood cells, liver, kidney, lung, heart) [17,18]. In mammals they are generated from enzymatic conversion of the naturally occurring all-cis PUFA by cytochrome P450 monooxygenases (CYP) leading to regioisomeric cis-epoxy-PUFA ( $R, S$ - and $S, R$-enantiomers, Fig. 1$)$ for each of the double bonds with distinct stereo- and regioselectivity depending on the respective involved CYP isoform [19,20]. Similarly to COX only the free, non-esterified PUFA are enzymatically converted by CYP, whereas in contrast to PG, epoxy-PUFA are mainly incorporated in lipids [21], e.g. predominantly the $s n-2$ position of phospholipids [22].

Apart from the CYP derived cis-epoxy-PUFA also trans-epoxy-PUFA ( $S, S$ - and $R, R$-enantiomers, Fig. 1 ) have been detected in red blood cells (RBC) [23] and heart tissue from untreated healthy animals [24]. Exposure of RBC with the oxidative stress causing agent tert-butylhydroperoxide $(t-\mathrm{BOOH})$ led to an increase of ARA derived epoxy-PUFA compared to control $[25,26]$. Regarding stereochemistry in response to $t-\mathrm{BOOH}$ treatment both diastereomers (i.e. cis and trans) increased in RBC, though a greater increase of trans-epoxy-ARA was observed [26].

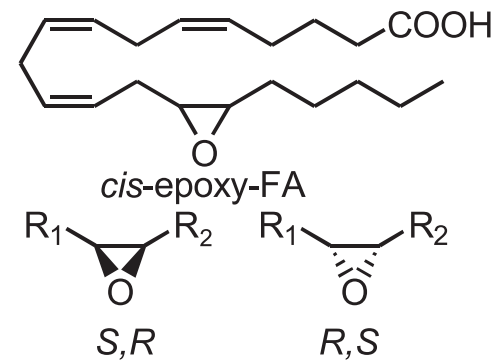

A favored formation of trans- over cis-epoxy-ARA was also observed after exposing ARA to radical starter in benzene and liposomes [24]. However, so far no information about the time course of trans-epoxyPUFA formation in biological settings and its correlation to the extent of oxidative stress is available.

In the present study we examined the formation of IsoP and epoxyPUFA following oxidative stress to investigate the potential use of transepoxy-PUFA and the trans/cis-epoxy-PUFA ratio as marker of oxidative stress. For this purpose, we extended an established LC-ESI(-)-MS/MS method covering enzymatically and non-enzymatically formed oxylipins to enable the separation and parallel quantification of cis- and trans-epoxy-PUFA. The concentration and time dependent generation of the oxidative lipid metabolites was examined in three cell lines from different human tissues and the model organism Caenorhabditis elegans (C. elegans) causing oxidative stress by treatment with $t-\mathrm{BOOH}$, and in murine kidney tissue after renal ischemia reperfusion injury (IRI). The parallel assessment of both, IsoP, known biomarker of oxidative stress, and epoxy-PUFA allowed us to demonstrate the applicability of the trans/cis-epoxy-PUFA ratio as oxidative stress marker.

\section{Materials and methods}

\subsection{Chemicals}

Standards of regioisomeric cis-epoxy-PUFA (mixture of $R, S$ - and $S, R$ enantiomers), isoprostane $15-\mathrm{F}_{2 \mathrm{t}}$-IsoP and the deuterated internal standards (IS) ${ }^{2} \mathrm{H}_{4}-15-\mathrm{F}_{2 \mathrm{t}}$-IsoP $\left({ }^{2} \mathrm{H}_{4}-8\right.$-iso- $\left.\mathrm{PGF}_{2 \alpha}\right),{ }^{2} \mathrm{H}_{11}-5(R, S)-5-\mathrm{F}_{2 \mathrm{t}}$-IsoP $\left({ }^{2} \mathrm{H}_{11}-( \pm) 5-\mathrm{iPF}_{2 \mathrm{a}}-\mathrm{VI}\right),{ }^{2} \mathrm{H}_{4}-9$ (10)-EpOME, ${ }^{2} \mathrm{H}_{11}-14(15)$-EpETrE were purchased from Cayman Chemicals (local distributor: Biomol, Hamburg, Germany). Other IsoP and IsoF standards from the biologically relevant PUFA $\alpha$-linolenic acid (18:3n3, ALA), ARA, eicosapentaenoic acid (20:5n3, EPA), adrenic acid (22:4n6, AdA), docosapentaenoic acid (22:5n6, DPA $\left.A_{n 6}\right)$, docosahexaenoic acid (22:6n3, DHA) [27] were synthesized according to our chemical strategies already described in the literature [28-32].

LC-MS-grade methanol (MeOH), LC-MS-grade acetonitrile (ACN), LC-MS-grade isopropanol and LC-MS-grade acetic acid were purchased from Fisher Scientific (Schwerte, Germany). Disodium hydrogen phosphate dihydrate and $n$-hexane (HPLC Grade) were obtained from Carl Roth (Karlsruhe, Germany). Potassium hydroxide (85\%) was obtained from Gruessing GmbH (Filsum, Germany). All other chemicals were purchased from Sigma Aldrich (Schnelldorf, Germany).

\subsection{Cell culture assay}

HCT-116 human colorectal carcinoma cells, Caki-2 human kidney carcinoma cells and HepG2 human liver carcinoma cells were grown in $10 \mathrm{~cm}$ dishes and incubated with $50 \mu \mathrm{M}$ and $200 \mu \mathrm{M}$ of $t$-BOOH (Sigma Aldrich, Schnelldorf, Germany) for $30 \mathrm{~min}, 1 \mathrm{~h}$ and $2 \mathrm{~h}$. The cells were harvested using trypsin as described and the cell pellets were stored at $-80^{\circ} \mathrm{C}$ until analysis [27]. Cell pellets typically contained $5 \times 10^{6}$ (HCT116), $4 \times 10^{6}$ (Caki-2) and $20 \times 10^{6}$ (HepG2) cells.

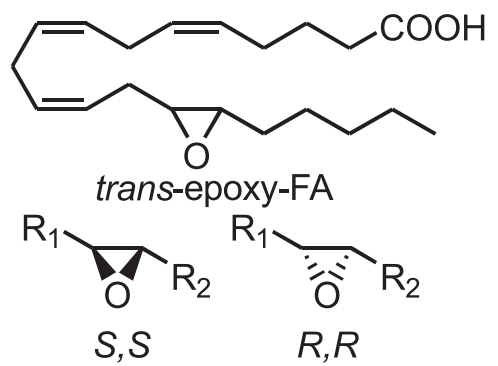

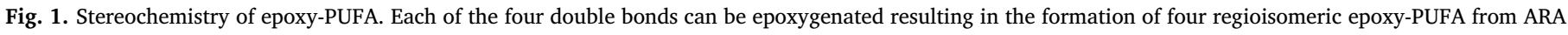

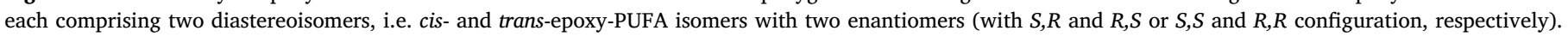


Cytotoxicity was assessed by the MTS assay (3-(4,5-dimethylthiazol2-yl)-5-(3-carboxymethoxyphenyl)-2-(4-sulfophenyl)-2H-tetrazolium) as described $[27,33]$. The used $t-\mathrm{BOOH}$ concentration showed no relevant effect on cell viability ( $>84 \%$ ) (SI Fig. S1, [27]).

\subsection{C. elegans treatment}

The N2 Bristol strain, provided by the Caenorhabditis Genetics Center (CGC; University of Minnesota), was propagated at $20^{\circ} \mathrm{C}$ on Nematode Growth Medium (NGM) plates spotted with the Escherichia coli strain OP50-1 [34]. Age-synchronized L4 stage worms were obtained by treating worms with an alkaline bleach solution $(1 \% \mathrm{NaClO}$ and $0.25 \mathrm{M} \mathrm{NaOH}$ ) and growing the hatched L1 larvae on OP50-1seeded NGM plates for approximately $48 \mathrm{~h}$. Treatment was performed using 12000 L4 stage worms. Therefore, the nematodes were exposed to $0,2.5 \mathrm{mM} t$-BOOH for $60 \mathrm{~min}$ or $6.5 \mathrm{mM} t$-BOOH for $15,30,45$ or $60 \mathrm{~min}$ in $85 \mathrm{mM} \mathrm{NaCl}$ containing $0.01 \%$ Tween $(6.5 \mathrm{mM}$ represents the lethal dose $50 \%$ (LD50) following $1 \mathrm{~h}$ exposure (data not shown)). Worms were then pelleted by centrifugation at $1600 \mathrm{rpm}$ for $2 \mathrm{~min}$ and washed four times in $85 \mathrm{mM} \mathrm{NaCl}$ containing $0.01 \%$ Tween. The remaining nematode pellet was snap-frozen in liquid nitrogen and stored at $-80^{\circ} \mathrm{C}$ until analysis.

\subsection{Renal ischemia reperfusion injury in mice}

C57BL/ $6 \mathrm{~J}^{\text {ham }-\mathrm{ztm}}$ male mice (12-13 weeks of age) were purchased from the institute of laboratory animal science (Hannover Medical School, Germany). Animals were cared for in accordance with the institution's guidelines for experimental animal welfare and with the guidelines of the American Physiological Society. The animal protection committee of the local authorities (Lower Saxony state department for food safety and animal welfare, LAVES) approved all experiments (approval 33.14-42502-04-14/1657). Mice were housed under conventional conditions with a $12 \mathrm{~h}$ light/dark cycle and had free access to food (Altromin 1324 standard mouse diet) and domestic quality drinking water ad libitum.

Surgery to induce renal IRI was done in general isoflurane anesthesia (5\% induction, $2 \%$ maintenance) in combination with iv analgetic treatment with butorphanol. IRI was induced by transient unilateral renal pedicle clamping for $35 \mathrm{~min}$ using a non-traumatic vascular clamp [35]. Mice were sacrificed $2 \mathrm{~h}, 4 \mathrm{~h}$ and $24 \mathrm{~h}$ after reperfusion by deep general anesthesia and total body perfusion with ice cold PBS. Kidneys were collected, immediately shock frozen and stored at $-80^{\circ} \mathrm{C}$ until oxylipin analysis.

\subsection{Quantification of oxylipins}

For the analysis of total, i.e. free and esterified oxylipins formed under different treatment conditions cell pellets (comprising $5 \times 10^{6}$ HCT-116, $4 \times 10^{6}$ Caki-2 or $20 \times 10^{6}$ HepG2 cells) and nematode pellets as well as kidney tissue samples $(25 \pm 3 \mathrm{mg}$ ) were extracted following alkaline hydrolysis using anion exchange Bond Elut Certify II SPE cartridges (Agilent, Waldbronn, Germany) as described [27,36].

In brief, to cell pellets (HCT-116, HepG2, Caki-2), C. elegans pellets and kidney tissue samples $10 \mu \mathrm{L}$ of IS solution $\left(100 \mathrm{nM}\right.$ of ${ }^{2} \mathrm{H}_{4}-15-\mathrm{F}_{2 \mathrm{t}^{-}}$ IsoP, ${ }^{2} \mathrm{H}_{11}-5-(R, S)-5-\mathrm{F}_{2 \mathrm{t}}$-IsoP, C19-17-epi-17- $\mathrm{F}_{1 \mathrm{t}}-\mathrm{PhytoP}, \mathrm{C} 21-15-\mathrm{F}_{2 \mathrm{t}^{-}}$ IsoP, ${ }^{2} \mathrm{H}_{4}$-6-keto- $\mathrm{PGF}_{1 \alpha},{ }^{2} \mathrm{H}_{4}-\mathrm{PGE}_{2},{ }^{2} \mathrm{H}_{4}-\mathrm{PGD}_{2},{ }^{2} \mathrm{H}_{4}-\mathrm{TxB}_{2},{ }^{2} \mathrm{H}_{4}-\mathrm{LTB}_{4},{ }^{2} \mathrm{H}_{4}-$ 9-HODE, ${ }^{2} \mathrm{H}_{8}$-5-HETE, ${ }^{2} \mathrm{H}_{8}$-12-HETE, ${ }^{2} \mathrm{H}_{6}$-20-HETE, ${ }^{2} \mathrm{H}_{11}-14,15-$ DiHETrE, ${ }^{2} \mathrm{H}_{11}-14(15)$-EpETrE, ${ }^{2} \mathrm{H}_{4}-9(10)$-EpOME and ${ }^{2} \mathrm{H}_{4}-9,10-$ DiHOME), $10 \mu \mathrm{L}$ of antioxidant solution $(0.2 \mathrm{mg} / \mathrm{mL}$ BHT and EDTA, $100 \mu \mathrm{M}$ indomethacin, $100 \mu \mathrm{M}$ of the soluble epoxide hydrolase inhibitor trans-4-[4-(3-Adamantan-1-yl-ureido)-cyclohexyloxy]-benzoic acid (t-AUCB) [37] in $\mathrm{MeOH} /$ water $(50 / 50, v / v))$ and $50 \mu \mathrm{L}$ water were added. The samples were homogenized after addition of $400 \mu \mathrm{L}$ isopropanol with a vibration ball mill (MM 400, Retsch, Haan, Germany) using two stainless steel beads ( $3 \mathrm{~mm}, 10 \mathrm{~min}, 25 \mathrm{~Hz}$ ).
After hydrolysis $\left(300 \mu \mathrm{L} 1.5 \mathrm{M} \mathrm{KOH}\left(25 / 75, \mathrm{H}_{2} \mathrm{O} / \mathrm{MeOH}, v / v\right)\right.$ for $30 \mathrm{~min}$ at $60^{\circ} \mathrm{C}$ ) the samples were immediately cooled, neutralized using acetic acid (50\%) and mixed with $2000 \mu \mathrm{L} 0.1 \mathrm{M}$ disodium hydrogen phosphate buffer $(\mathrm{pH}=6)$ followed by SPE. After sample loading, the cartridges were washed with one column volume of each water and $\mathrm{MeOH} /$ water $(50 / 50, v / v)$ and dried. The analytes were eluted with $2 \mathrm{~mL}$ of $75 / 25(v / v)$ ethylacetate/n-hexane with $1 \%$ acetic acid, evaporated and the residue was resuspended in $50 \mu \mathrm{L} \mathrm{MeOH}$ (containing $40 \mathrm{nM}$ of 1-(1-(ethylsulfonyl)piperidin-4-yl)-3-(4-(trifluoromethoxy)phenyl)urea as IS2 for the calculation of the extraction efficiency of the IS). After centrifugation $\left(10 \mathrm{~min}, 4^{\circ} \mathrm{C}, 20,000 \times \mathrm{g}\right)$ the samples were analyzed by RP-LC-MS/MS (6500 QTRAP, Sciex, Darmstadt, Germany) in scheduled selected reaction monitoring mode following negative electrospray ionization as described [27].

\subsection{Data analysis}

Oxylipin concentrations were quantified using external calibration with authentic standards (linear fitting with $1 / \mathrm{x}^{2}$ weighting) based on the analyte to corresponding IS area ratio as described [27]. For each epoxy-fatty acid regioisomer both cis- and trans-epoxy-PUFA isomers were quantified using the calibration curve of corresponding cis-epoxyPUFA (identified with authentic standards). Based on that, the trans/cisepoxy-PUFA ratios were calculated. For 7(8)-EpDPE and 5(6)-EpETE due to absence of accurate quantitative standards only the trans/cisepoxy-PUFA ratio could be determined. Trans-epoxy-PUFA isomers eluting $0.14-0.3 \mathrm{~min}$ after their corresponding cis-isomers (SI Fig. S2) were identified based on retention time and identical MS-fragmentation pattern as described [23,24,26].

Data evaluation and statistical analyses were performed as indicated using GraphPad Prism version 6.01 for Windows (GraphPad Software, La Jolla California USA, www.graphpad.com).

\section{Results}

In the present study using a comprehensive LC-MS/MS method total, i.e. free and esterified, levels of IsoP as well as cis- and transepoxy-PUFA derived from different precursor PUFA were simultaneously quantified in cell pellets and $C$. elegans incubated with oxidative stress generating $t$ - $\mathrm{BOOH}$ and in murine kidney tissue after renal ischemia reperfusion injury.

\subsection{Formation of IsoP}

\subsubsection{IsoP in cells following treatment with $\mathrm{t}-\mathrm{BOOH}$}

In cell pellets from colorectal (HCT-116), renal (Caki-2) and hepatic (HepG2) origin 6 IsoP regioisomers derived from 4 precursor PUFA (ARA, EPA, DHA, AdA) were quantified. Regarding detected isomers the regioisomers carrying the hydroxyl group in proximity to the carboxy function, i.e. ARA derived $5(R, S)-5-\mathrm{F}_{2 \mathrm{t}}$-IsoP, EPA derived $5(R, S)-5$ $\mathrm{F}_{3 \mathrm{t}}$-IsoP, DHA derived $4(R, S)-4-\mathrm{F}_{4 \mathrm{t}}$-NeuroP and AdA derived ent-7 $(R, S)$ $7-\mathrm{F}_{2 \mathrm{t}}$-dihomo-IsoP showed higher concentration than other regioisomers from the same PUFA or were the only regioisomers detected as it is the case for AdA derived $\mathrm{F}_{2 \mathrm{t}}$-dihomo-IsoP. Under basal conditions in HCT-116 cells only $5(R, S)-5-\mathrm{F}_{2 \mathrm{t}^{-}}-\mathrm{IsoP}, 5(R, S)-5-\mathrm{F}_{3 \mathrm{t}^{-}} \mathrm{IsoP}$ and $4(R, S)-4-\mathrm{F}_{4 \mathrm{t}^{-}}$ NeuroP were detected while in Caki-2 and HepG2 cells additionally other regioisomers $\left(15-\mathrm{F}_{2 \mathrm{t}}\right.$-IsoP and $10(R, S)-10-\mathrm{F}_{4 \mathrm{t}}$-NeuroP) were found. Interestingly, basal levels of detected IsoP in Caki-2 cells were 2-7 fold higher than in HepG2 and 6-20 fold higher than in HCT-116 cells. In all cell lines incubation with $t$ - $\mathrm{BOOH}$ led to an increase in IsoP formation, however the dose and time dependent pattern showed considerable differences between the cell types, though being similar for all regioisomers within the individual cell types (Fig. 2). In HCT-116 cells a dose dependent increase of IsoP level was observed leading to 3-5 fold and 10-17 fold higher IsoP concentrations compared to control with $50 \mu \mathrm{M}$ and $200 \mu \mathrm{M} t$-BOOH respectively (Fig. 2I). While with 50 
(I) HCT-116

(A) IsoP
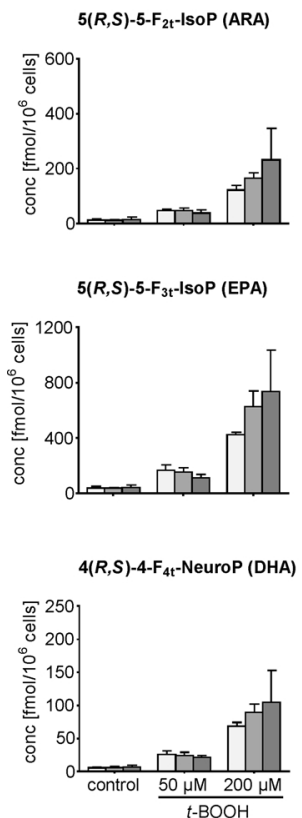

(B) epoxy-PUFA
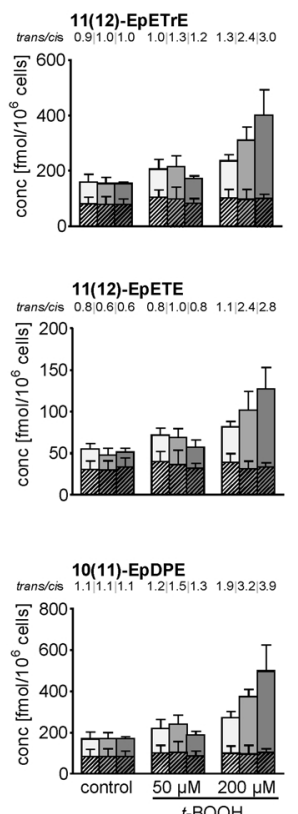

(II) HepG2

(A) IsoP
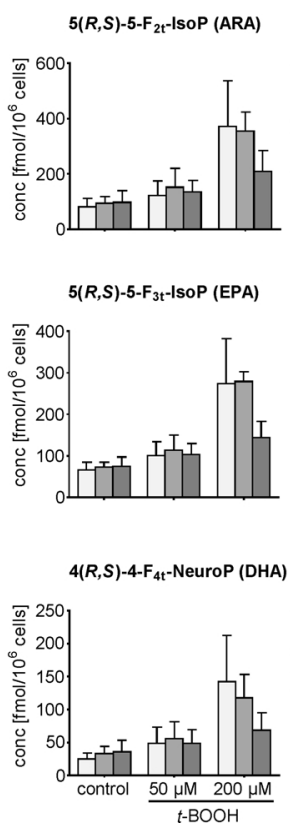

(B) epoxy-PUFA
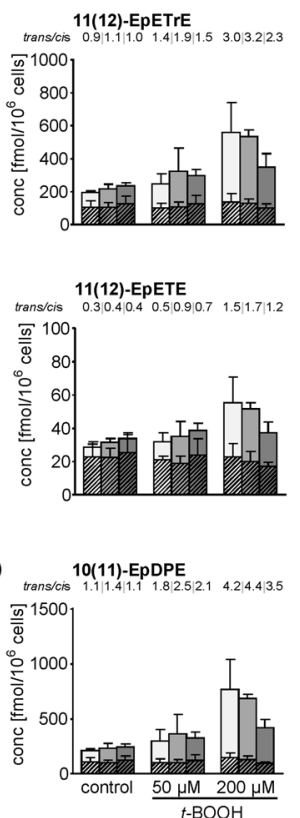

IsoP / trans-epoxy-PUFA $\square 0.5 \mathrm{~h} \quad \square 1 \mathrm{~h} \square 2 \mathrm{~h}$

cis-epoxy-PUFA $0.5 \mathrm{~h} \quad 1 \mathrm{~h} \quad 2 \mathrm{~h}$

\section{(III) Caki-2}

(A) IsoP
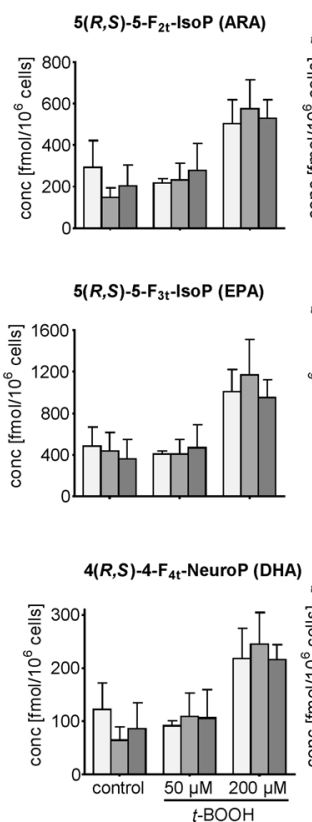

(B) epoxy-PUFA
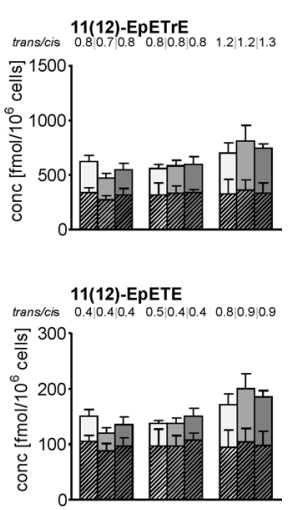

Fig. 2. Total levels of representative (A) IsoP and (B) epoxy-PUFA derived from ARA, EPA and DHA following incubation of (I) HCT-116, (II) HepG2 and (III) Caki-2 cells with $50 \mu \mathrm{M}$ and $200 \mu \mathrm{M} t$-butyl hydroperoxide $(t-\mathrm{BOOH})$ for $0.5 \mathrm{~h}, 1 \mathrm{~h}$ and $2 \mathrm{~h}$. Shown are mean \pm SD (HCT-116: $\mathrm{n}=4, \mathrm{HepG} 2: \mathrm{n}=3$, Caki-2: $\mathrm{n}=4$ ). For epoxy-PUFA the trans/cis-epoxy-PUFA-ratio (trans/cis) is indicated above the corresponding bars.

$\mu \mathrm{M} t$-BOOH no effect of the incubation time $(0.5 \mathrm{~h}-2 \mathrm{~h})$ was observed, $200 \mu \mathrm{M} t-\mathrm{BOOH}$ induced a trend towards higher IsoP levels with longer incubation time. In HepG2 cells only $200 \mu \mathrm{M}$ of $t$-BOOH led to an increase of IsoP levels compared to control (Fig. 2II). Interestingly, with longer incubation time a decrease in IsoP concentrations was observed leading at $2 \mathrm{~h}$ to almost same concentrations as with $50 \mu \mathrm{M} t$-BOOH. In Caki-2 cells only incubation with $200 \mu \mathrm{M} t$-BOOH led to a slight increase of IsoP concentrations, however here no time dependent change of IsoP levels was observed (Fig. 2III).

\subsubsection{IsoP in C. elegans following treatment with $t-B O O H$}

In nematode pellets of wildtype $\mathrm{N} 2 C$. elegans only EPA derived $5(R, S)-5-\mathrm{F}_{3 \mathrm{t}}$-IsoP were detected in the control group. Incubation with $t$ $\mathrm{BOOH}$ led to an increase and additional formation of EPA derived $8(R, S)-8-\mathrm{F}_{3 \mathrm{t}^{-}}$-IsoP as well as ARA derived $15-\mathrm{F}_{2 \mathrm{t}^{-}} \mathrm{IsoP}$ and $5(R, S)-5-\mathrm{F}_{2 \mathrm{t}^{-}}$ IsoP. A dose dependent increase in IsoP levels was observed with the applied $t$-BOOH concentration leading to 4-6 fold higher IsoP levels for $6.5 \mathrm{mM}$ compared to $2.5 \mathrm{mM} t$-BOOH after $60 \mathrm{~min}$ incubation (Fig. 3I). Also, longer incubation time led to a gradual increase resulting in 46 fold higher IsoP levels for $60 \mathrm{~min}$ compared to $15 \mathrm{~min}$ incubation with $6.5 \mathrm{mM} t$-BOOH (Fig. 3II).

\subsubsection{IsoP in murine kidneys after ischemia reperfusion injury}

In murine kidney tissue ARA derived $5(R, S)-5-\mathrm{F}_{2 \mathrm{t}}-\mathrm{IsoP}$ and $15-\mathrm{F}_{2 \mathrm{t}^{-}}$ IsoP and DHA derived $4(R, S)-4-\mathrm{F}_{4 \mathrm{t}}-\mathrm{NeuroP}$ and $10(R, S)-10-\mathrm{F}_{4 \mathrm{t}}-\mathrm{NeuroP}$ were detected with higher levels of the regioisomers carrying the hydroxyl group in proximity to the carboxy function. While in IRI tissue $2 \mathrm{~h}$ after reperfusion higher levels of ARA derived IsoP were observed compared to unclamped contralateral kidney tissue, DHA derived NeuroP remain almost unchanged. $4 \mathrm{~h}$ after reperfusion higher levels for both, ARA and DHA derived IsoP were observed in IRI tissue compared to unclamped control. Interestingly, $24 \mathrm{~h}$ after unilateral IRI lower levels of DHA derived NeuroP were observed in the IRI kidney compared to the contralateral unclamped kidney, while levels of ARA derived IsoP were similar in the IRI and unclamped kidney (Fig. 4).

\subsection{Formation of epoxy-PUFA}

\subsubsection{Epoxy-PUFA in cells following treatment with $t-B O O H$}

In cell pellets from colorectal (HCT-116), renal (Caki-2) and hepatic (HepG2) origin for all epoxy-PUFA derived from ARA (i.e. EpETrE), EPA (i.e. EpETE) and DHA (i.e. EpDPE) cis- and trans-isomers could be determined. However as a result of chromatographic interference in HCT-116 cells cis-19(20)-EpDPE and in HepG2 cells cis-8(9)-EpETE were not evaluable.

In control incubations the trans/cis-epoxy-PUFA ratios of the respective regioisomers were similar between the different cell types, however differed between the individual regioisomers. While for most regioisomers levels of cis-isomers were higher than of trans-isomers, for regioisomers carrying the epoxy moiety in the middle or front part of the carbon chain (i.e. 8(9)-EpETrE, 11(12)-EpETrE, 5(6)-EpETE, 7(8)EpDPE and 10(11)-EpDPE) the ratios of trans/cis-isomers were approximately equal (0.7-1.4) or higher as for 5(6)-EpETrE (trans/cisratio $>1.5$ ).

Incubation with $t$-BOOH led in all cell lines to an increase of transepoxy-PUFA levels, while levels of respective cis-isomers remained almost constant, resulting in an increase of the trans/cis-epoxy-PUFA ratios. However, dose and time dependent formation of trans-epoxyPUFA differed between the investigated cell lines with the individual regioisomers showing the same pattern within the particular cell types irrespective of the precursor PUFA (Fig. 2). In HCT-116 cells with 50 $\mu \mathrm{M} t$-BOOH trans-epoxy-PUFA remained almost constant, whereas 200 $\mu \mathrm{M} t$-BOOH led to 1.7-6.6 fold higher levels of trans-isomers compared to control. Regarding incubation time, only with $200 \mu \mathrm{M} t$-BOOH a trend towards higher levels of trans-epoxy-PUFA with longer incubation was observed, leading to a 1.7-2.7 fold increase of the trans/cis-ratios 
(I) Dose dependent formation after $60 \mathrm{~min}$

IsoP / trans-epoxy-PUFA $\square$ control $\square 2.5 \square 6.5 \mathrm{mM} t$-BOOH

cis-epoxy-PUFA $\square$ control $2.5 \square 6.5 \mathrm{mM} t$ - $\mathrm{BOOH}$
(II) Time dependent formation at $6.5 \mathrm{mM} t-\mathrm{BOOH}$

IsoP / trans-epoxy-PUFA $\square$ control $\square 15 \square 30 \square 45 \square 60 \mathrm{~min} t$-BOOH

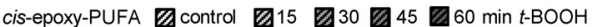

(A) IsoP

(B) epoxy-PUFA

$5(R, S)-5-F_{2 t}$-IsoP (ARA) ARA derived EpETrE trans/cis $\quad 0.1|0.2| 0.4 \quad 0.2|0.2| 0.6 \quad 0.4|0.4| 0.8$
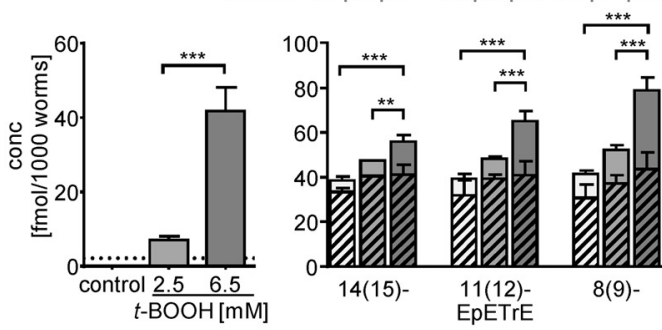

EPA derived EpETE

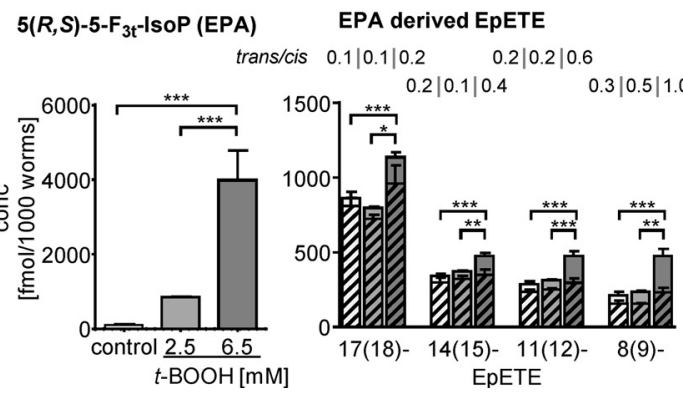

(A) IsoP

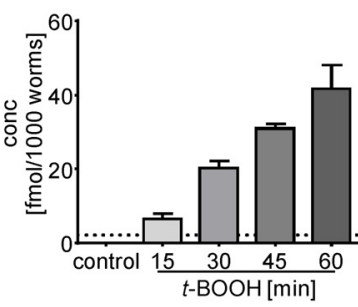

$5(R, S)-5-F_{3 t^{-}}$ISOP (EPA)
$5(R, S)-5-F_{2 t}$-ISOP (ARA)

\section{(B) epoxy-PUFA}

ARA derived EpETrE

$0.1|0.2| 0.3|0.3| 0.4 \quad 0.2|0.3| 0.4|0.5| 0.6 \quad 0.4|0.4| 0.6|0.7| 0.8$

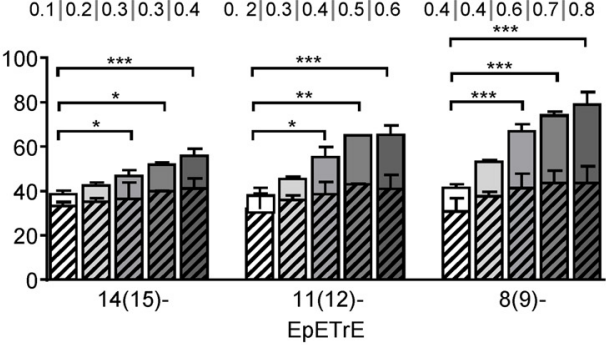

EPA derived EpETE

$0.1|0.1| 0.1|0.2| 0.2 \quad 0.2|0.3| 0.5|0.6| 0.6$

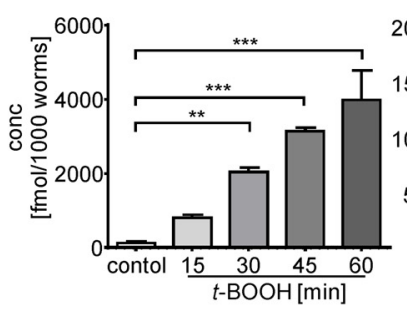
$0.2|0.2| 0.3|0.3| 0.4$

$0.3|0.6| 0.8|1.0| 1.0$
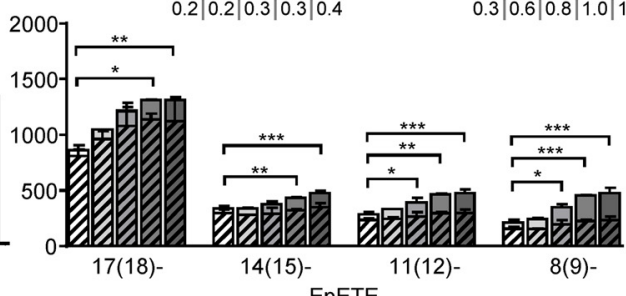

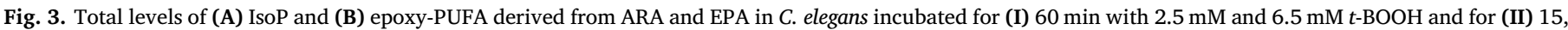

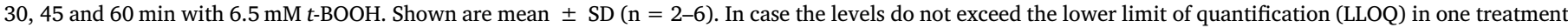

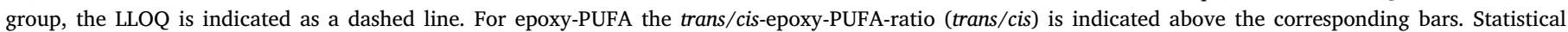

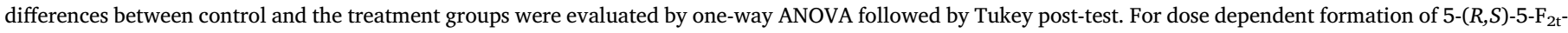

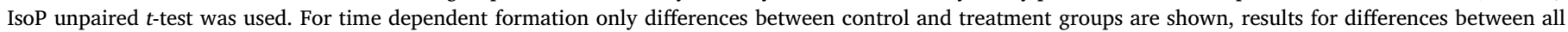
treatments groups are summarized in SI Tab. S1 (* p $<0.05$, ** $\mathrm{p}<0.01$, *** $\mathrm{p}<0.001)$.

\section{(A) IsoP}

$$
5(R, S)-5-\mathrm{F}_{2 \mathrm{t}} \text {-ISOP (ARA) }
$$
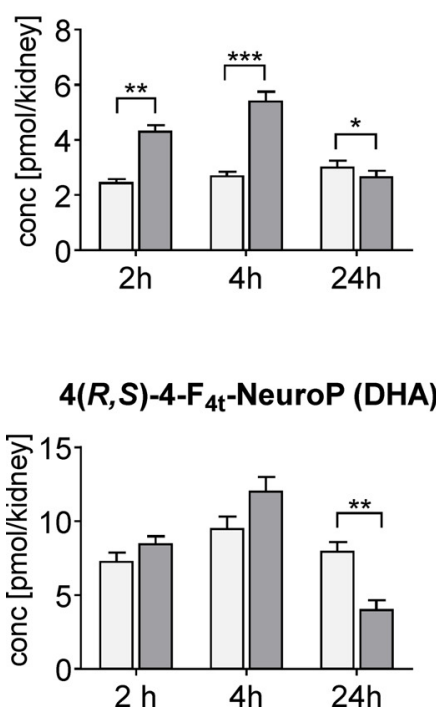

\section{(B) epoxy-PUFA}
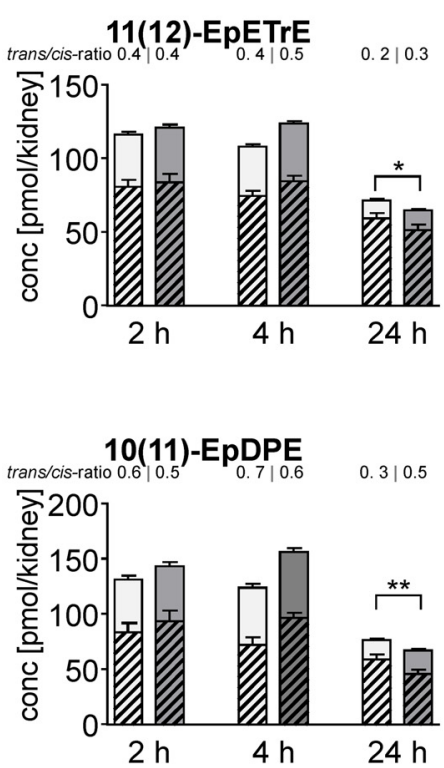

Fig. 4. Total levels of (A) IsoP and (B) epoxy-PUFA derived from ARA and DHA in murine kidney tissue following unilateral IRI for $35 \mathrm{~min}$. Shown are mean $\pm \operatorname{SEM}(n=6)$ in the unclamped and IRI kidneys $2 \mathrm{~h}, 4 \mathrm{~h}$ and $24 \mathrm{~h}$ after reperfusion. For epoxy-PUFA the trans/cis-epoxy-PUFA-ratio (trans/ cis-ratio) is indicated above the corresponding bars. Statistical differences between the unclamped and IRI kidneys were evaluated by paired t-test for 5- $(R, S)-5-\mathrm{F}_{2 \mathrm{t}}$-IsoP, 4(R,S)-4- $\mathrm{F}_{4 \mathrm{t}}$-NeuroP and the trans/cis-epoxy-PUFA ratios (* $\mathrm{p}<0.05, \quad * * \quad \mathrm{p}<0.01, \quad * * *$ $\mathrm{p}<0.001)$. for $1 \mathrm{~h}$ and $2 \mathrm{~h}$ compared to $0.5 \mathrm{~h}$ incubation (Fig. 2I). In HepG2 cells 50 $\mu \mathrm{M} t$-BOOH led only to a slight increase of the trans/cis-ratios (1.5-1.8 fold), while with $200 \mu \mathrm{M} t$-BOOH trans/cis-ratios were 2.0-5.2 fold higher compared to control. Similarly to HCT-116 cells with $50 \mu \mathrm{M} t$ $\mathrm{BOOH}$ cis- and trans-isomer levels remained almost unchanged with longer incubation time. In contrast, with $200 \mu \mathrm{M} t$-BOOH levels of transepoxy-PUFA increased after $0.5 \mathrm{~h}$ and remain similar after $1 \mathrm{~h}$, however after $2 \mathrm{~h}$ of incubation a trend towards lower levels of cis- and transepoxy-PUFA was observed (Fig 2II). In Caki-2 cells only with $200 \mu \mathrm{M} t$ $\mathrm{BOOH}$ a slight trend towards higher levels of trans-epoxy-PUFA was observed, however neither $50 \mu \mathrm{M}$ nor $200 \mu \mathrm{M} t$ - $\mathrm{BOOH}$ led to a time dependent change of epoxy-PUFA levels (Fig. 2III). 


\subsubsection{Epoxy-PUFA in C. elegans following treatment with $t-B O O H$}

In non-exposed wildtype N2 C.elegans cis- and trans-isomers of all analyzed epoxy-PUFA regioisomers derived from ARA and EPA were detected. Levels of EPA derived epoxy-PUFA were markedly higher than ARA derived epoxy-PUFA. Interestingly, levels of the terminal regioisomers, i.e. 14(15)-EpETrE and 17(18)-EpETE, were different compared to the other regioisomers. While levels of ARA derived regioisomers were in the same range, 17(18)-EpETE showed 2.7-5.2 fold higher basal levels than the other EPA derived regioisomers. Incubation with $t$-BOOH led to a dose and time dependent increase in epoxy-PUFA levels. With $2.5 \mathrm{mM} t$-BOOH for $60 \mathrm{~min}$ both, cis- and trans-isomers showed a slight but similar trend towards higher levels compared to control resulting in unchanged trans/cis-ratios. Further increasing the applied $t-\mathrm{BOOH}$ concentration to $6.5 \mathrm{mM}$ led to a favored formation of trans- over cis-isomers, leading to a 2.3-2.9 fold increase in trans/cisratios compared to control (Fig. 3I). A similar pattern was also observed regarding incubation time with $6.5 \mathrm{mM} t$-BOOH. While after $15 \mathrm{~min}$ cisand trans-isomers increased only slightly though to a similar extent, longer incubation (30-60 $\mathrm{min}$ ) resulted in a favored formation of transover cis-isomers. Consequentially trans/cis-ratios increased gradually with longer incubation time resulting in 1.7-2.4 fold higher trans/cisratios for $60 \mathrm{~min}$ compared to $15 \mathrm{~min}$ incubation (Fig. 3II).

\subsubsection{Epoxy-PUFA in murine kidney after ischemia reperfusion injury}

In murine kidney tissue only for ARA and DHA derived epoxy-PUFA regioisomers cis- and trans-isomers were detected. For both precursor PUFA basal levels of individual epoxy-PUFA regioisomers showed a distinct distribution of trans- and cis-isomers depending on the position of the epoxy-moiety relative to the carboxy-function: the closer the epoxy-moiety to the carboxy terminus the higher the observed trans/cisratio (SI Fig. S3). Following unilateral IRI, $2 \mathrm{~h}$ after reperfusion levels of epoxy-PUFA remained almost unchanged, while $4 \mathrm{~h}$ after reperfusion both cis- and trans-epoxy-PUFA showed a slight increase compared to unclamped kidney resulting in almost unchanged trans/cis-ratios. $24 \mathrm{~h}$ after reperfusion levels of ARA derived epoxy-PUFA were similar in IRI and unclamped tissue. While in contrast for DHA derived epoxy-PUFA a decrease of cis-isomers was observed in IRI compared to unclamped kidney tissue with almost unchanged trans-epoxy-PUFA level. Interestingly, this decrease was more pronounced for terminal isomers, i.e. 19(20)- and 16(17)-EpDPE compared to 13(14)- and 10(11)-EpDPE (Fig. 4, SI Fig. S3).

\subsubsection{Correlation of IsoP}

In cell lines as well as in $C$. elegans following incubation with $t$ $\mathrm{BOOH}$ a clear correlation between IsoP formation and the trans/cisepoxy-PUFA ratio was found (Fig. 5, Table 1). Pearson correlations between the levels of IsoP regioisomers carrying the hydroxyl group in proximity to the carboxy-function and the ratio of trans/cis-epoxy-PUFA regioisomers from the corresponding PUFA were determined (Table 1): ARA derived 5(R,S)-5 $\mathrm{F}_{2 \mathrm{t}}$-IsoP was correlated with EpETrE regioisomers, EPA derived $5(R, S)-5-\mathrm{F}_{3 \mathrm{t}}$-IsoP with EpETE regioisomers and DHA derived $4(R, S)-4-\mathrm{F}_{4 \mathrm{t}}$-NeuroP with EpDPE regioisomers. For all epoxy-PUFA regioisomers positive and highly significant correlations with IsoP levels were obtained in the three cell lines and C. elegans (Fig. 5, Table 1). As no significant increase in the trans/cis-ratio was found in murine renal IRI (Fig. 4, SI Fig. S3) consequently no correlation of IsoP levels and trans/cis-epoxy-PUFA ratios resulted.

\section{Discussion}

In the present study total levels of IsoP and cis- and trans-epoxyPUFA were simultaneously quantified. Based on that, the correlation between these autoxidatively formed oxylipins during oxidative stress was evaluated in three models: (i) $t$ - $\mathrm{BOOH}$ induced stress in three cultured cell lines and in (ii) C. elegans and (iii) following ischemic reperfusion injury in the kidney in mice.
ARA derived $\mathrm{F}_{2}$-IsoP are well established marker of oxidative damage formed during lipid peroxidation in vivo. Particularly $15-\mathrm{F}_{2 \mathrm{t}}$-IsoP (8-iso-PGF $\mathrm{PG}_{2 \alpha}$ ) is commonly used as biomarker in diseases and environmental exposures related to oxidative stress $[8,9,11]$. In line we found a strong increase of IsoP in response to $t-\mathrm{BOOH}$ in all cell lines as well as in C. elegans (Fig. 2 and 3). The modulation of IsoP was markedly different between the cell lines regarding both, dose and time dependency: while in HCT-116 cells already $50 \mu \mathrm{M} t$-BOOH led to an increase in IsoP levels, in HepG2 and Caki-2 cells a trend towards higher IsoP levels was only observed in incubations with $200 \mu \mathrm{M} t$-BOOH (Fig. 2). This could result from different intracellular RONS detoxifying mechanisms between the cell types, breaking down $t$ - $\mathrm{BOOH}$ generated radicals and preventing oxidative damage. It seems that only if a threshold in intracellular ROS burden is reached, an increased IsoP formation results. For HCT-116 cells this level seems to be reached at $t$-BOOH levels above $50 \mu \mathrm{M}$ while for Caki-2 cells only at a high concentration of $200 \mu \mathrm{M} t$ $\mathrm{BOOH}$ IsoP levels are elevated. A threshold of oxidative stress inducing noxae for the formation of IsoP depending on the concentration of oxidative stress inducer was also observed previously in HepG2 cells treated with the redoxcycler paraquat [38]. Here only incubation with concentrations equal or above $100 \mu \mathrm{M}$ led to an increase in IsoP formation compared to control.

Noteworthy, with high concentration of $t-\mathrm{BOOH}(200 \mu \mathrm{M})$ for all detected regioisomers, IsoP level showed a distinct time dependent pattern in the different cell lines. In HCT-116 cells a trend towards higher level of IsoP with longer incubation time was observed (Fig. 2I). Consistently, a similar time dependent increase of IsoP was previously reported for copper induced peroxidation of ARA and EPA containing phospholipids or of cell lysates [38,39]. In contrast, in HepG2 cells levels of IsoP showed a decreasing trend with longer incubation and remained unaffected by the incubation time in Caki-2 cells (Fig. 2). A decrease in total IsoP levels as observed in HepG2 cells might result from metabolic degradation of the formed oxylipins. As formation of IsoP occurs in situ on phospholipids [7] hydrolysis of IsoP containing phospholipids by phospholipase A2 seems likely to be involved in the observed decrease of total IsoP level. Indeed, the intracellular type II platelet-factor-acetyl hydrolase exhibiting negligible phospholipase activity against long chain-PUFA containing membrane phospholipids [40,41] hydrolyses $\mathrm{F}_{2}$-IsoP containing phospholipids [42] and was shown to translocate from the cytosol to the membrane upon oxidative stress stimulus [43]. Furthermore, a time course similar to the one observed in HepG2 cells was also observed following $\mathrm{CCl}_{4}$ induced peroxidation in the rat [7]. Here, total IsoP levels in the liver increased rapidly after $\mathrm{CCl}_{4}$ was applied with a peak after $2 \mathrm{~h}$, however were followed by a decrease over time leading to almost restored levels after $24 \mathrm{~h}$. Correspondingly, plasma level of free IsoP arising from release of esterified IsoP showed a similar, however delayed time course, further supporting the hypothesis of phospholipase contribution.

Among the multitude of different IsoP regio- and stereoisomers that can be formed during lipid peroxidation (e.g. for ARA a total of 64 different $\mathrm{F}_{2}$-isomers) [5], we observed a favored formation of selected regioisomers in all investigated cell lines, C. elegans as well as kidney tissue. Regarding IsoP isomers covered in our analysis, regioisomers carrying the side chain hydroxy group in proximity to the carboxy group, i.e. ARA derived $5(R, S)-5-\mathrm{F}_{2 \mathrm{t}^{-}}$-IsoP, EPA derived $5(R, S)-5-\mathrm{F}_{3 \mathrm{t}^{-}}$ IsoP, DHA derived $4(R, S)-4-\mathrm{F}_{4 \mathrm{t}}$-NeuroP and AdA derived ent-7 $(R, S)-7$ $\mathrm{F}_{2 \mathrm{t}}$-dihomo-IsoP, were observed in higher abundance than its regioisomers. This is consistent with previous studies where a preferential formation of particular regioisomers was observed. Similarly to our results for ARA the 5- and $15-\mathrm{F}_{2 \mathrm{t}}$-IsoP, for EPA the 5- and $18-\mathrm{F}_{3 \mathrm{t}}$-IsoP [44] and for DHA the 4- and 20- $\mathrm{F}_{4 \mathrm{t}}$-NeuroP [45] regioisomers were observed in greater abundance. This may be explained by further oxidative conversion of the precursor involved in the formation of other IsoP regioisomers during autoxidation. One could also expect, that the regioisomers bearing the hydroxy-group at C4 or C5 position are also more stable towards $\beta$-oxidation which could contribute to higher 
(A) HCT-116
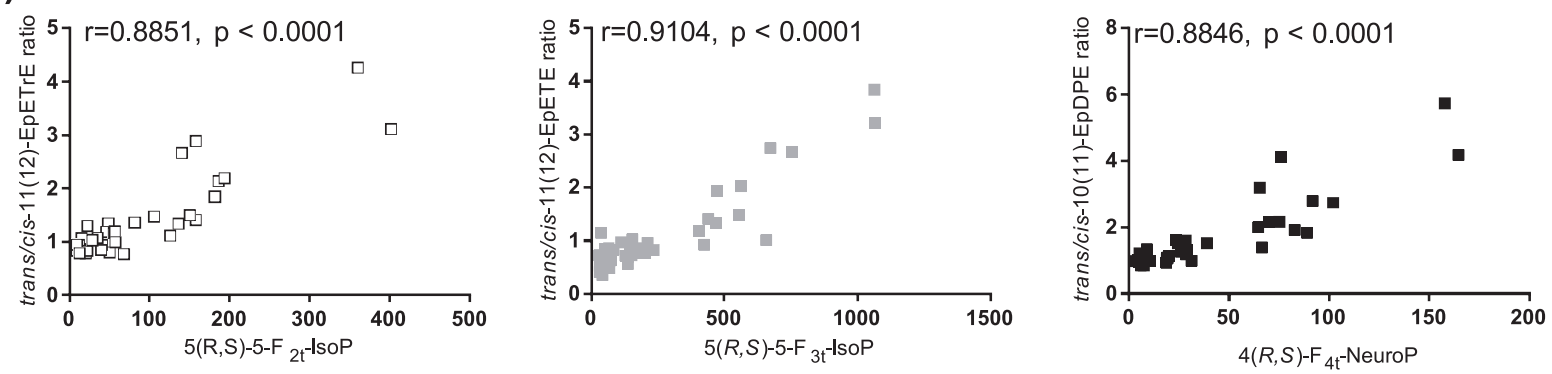

\section{(B) HepG2}
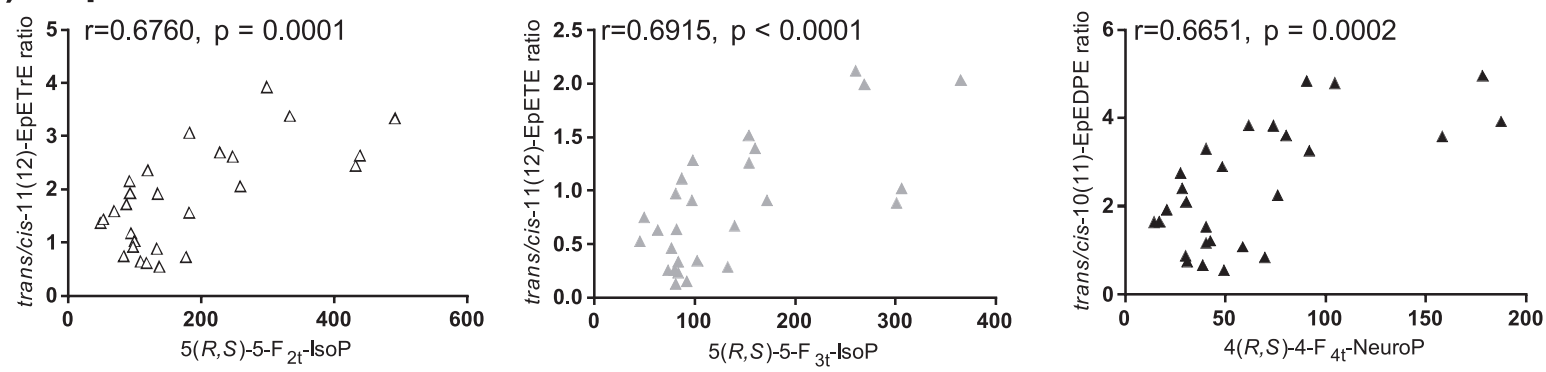

\section{(C) Caki-2}
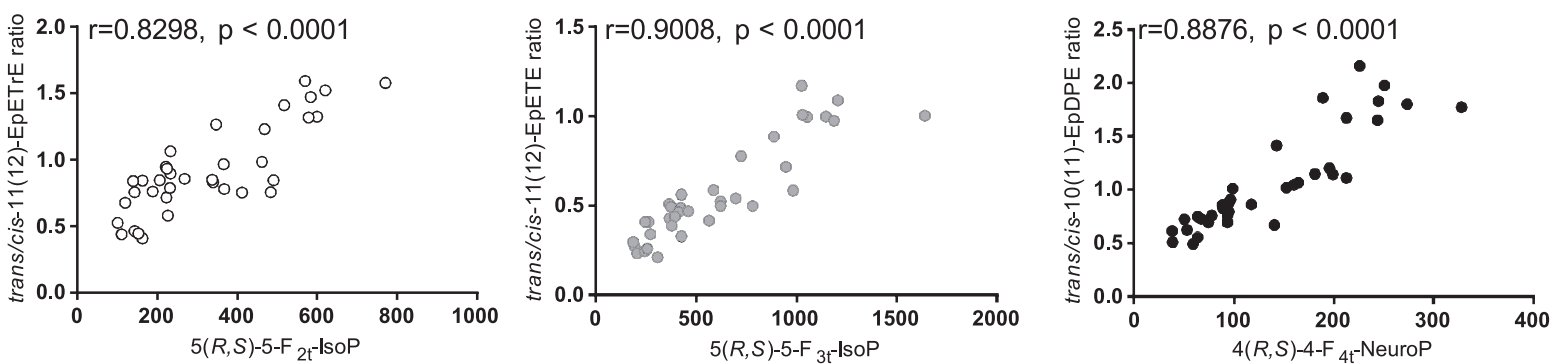

(D) C. elegans
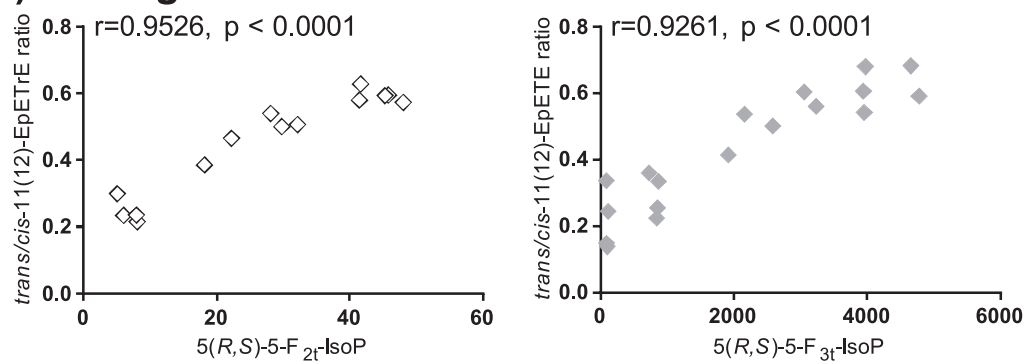

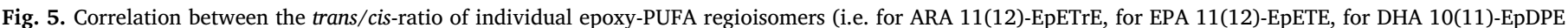

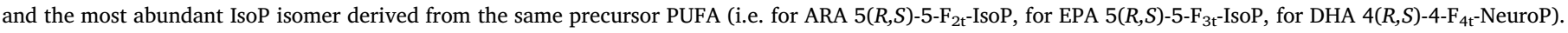

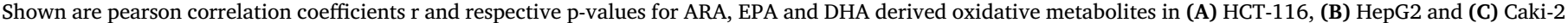
cells, as well as (D) C. elegans incubated with $t$-BOOH.

levels of these regioisomers, as has been observed previously for other 5-hydroxyeicosanoids (e.g. leukotriens) [46,47].

Remarkably, in all cell lines, levels of these regioisomers were in a similar range for ARA, EPA and DHA derived IsoP (Fig. 2) while in $C$. elegans levels of EPA derived $5(R, S)-5-\mathrm{F}_{3 \mathrm{t}}$-IsoP were considerably higher than the corresponding ARA derived regioisomer (Fig. 3). As PUFA serve as substrates for IsoP formation, the fatty acid composition and PUFA pattern affect the level of respective formed IsoP. Consistently, the observed high level of EPA derived $\mathrm{F}_{3}$-IsoP in $C$. elegans is in agreement with the predominant relative EPA content compared to
ARA [48].

Regarding formation of epoxy-PUFA, the trans/cis-epoxy-PUFA ratio increased with the applied $t$-BOOH concentration in all cell lines and $C$. elegans and showed a distinct time dependent pattern in the different cell lines (Fig. 2 and 3). The similar pattern in comparison with the observed IsoP level suggests the contribution of related mechanisms (discussed above). Overall the increase in the trans/cis-epoxy-PUFA ratio was mainly caused by a favored formation of trans- compared to $c i s$-isomers during $t$ - $\mathrm{BOOH}$ induced oxidative stress. This supports previous findings demonstrating formation of epoxy-PUFA during 


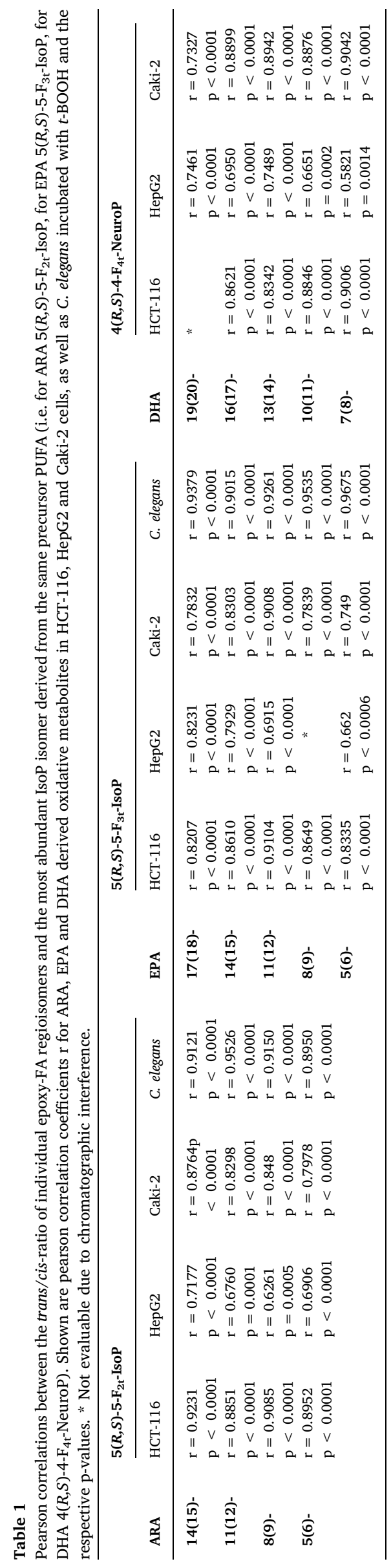

autoxidation, as has been shown for ARA derived EpETrE in RBC incubated with $t$-BOOH $[25,26]$. Consistently, both, free radical induced peroxidation in benzene and liposomes as well as exposure of RBC to $t$ $\mathrm{BOOH}$ led to a favored formation of trans- over cis-epoxy-ARA [24,26]. As double bonds in naturally occurring PUFA are oriented all-cis a possible mechanism leading to the formation of both, cis- and transepoxy-PUFA could involve PUFA carbon centered radicals with an adjacent peroxyl group. These are formed at the position of the double bond in the PUFA molecule during the radical chain reaction. These carbon radicals allow for free rotation of the $\sigma$-bond prior intramolecular attack of the peroxyl bond by the reactive carbon radical which leads via homolytic substitution to the formation of an epoxymoiety oriented either cis or trans [4,24].

Irrespective of the precursor PUFA the observed increase in the trans/cis-epoxy-PUFA ratio following $t$-BOOH induced oxidative stress was similar for all regioisomers, though being slightly higher for $5(6)$ EpETE. However, this has to be regarded with caution as 5(6)-EpETE, like 5(6)-EpETrE might rapidly degrade forming a six-membered $\delta$ lacton [49]. Additionally, also high basal levels of cis-epoxy-PUFA derived from CYP as observed for the preferred formation of the $\omega 3$ epoxygenation product 17(18)-EpETE compared to its other regioisomers in C. elegans (Fig. 3) might hamper the suitability of the respective trans/cis-ratio reflecting the oxidative damage.

Here, we tested for the first time if the trans/cis-epoxy-PUFA ratio can reflect oxidative stress. For this purpose we correlated the trans/cisepoxy-PUFA ratio with level of IsoP which are established biomarker of lipid peroxidation. Considering the consistent time and $t$-BOOH concentration dependent pattern, quite clear, positive highly significant correlations of IsoP level with the trans/cis-epoxy-PUFA ratio were observed for all epoxy-PUFA regioisomers in $t$ - $\mathrm{BOOH}$ induced oxidative stress in all three cell lines and C. elegans (Fig. 5, Table 1). Thus, we suggest that the trans/cis-epoxy-PUFA ratio might serve as alternative oxidative stress marker.

However, in the evaluated invivo model of murine renal IRI, the moderate increase of IsoP was not accompanied by an increase in the trans/cis-epoxy-PUFA ratio (Fig. 4, SI Fig. S3). Thus, here the applicability of the trans/cis-epoxy-PUFA ratio as oxidative stress marker cannot be evaluated based on comparison with IsoP levels. Even though IRI is linked to excess ROS formation [50,51] and an increase of oxidative damage derived IsoP following renal IRI has been observed in rat models [52,53], there are various factors influencing measured IsoP levels in this model. These include clamping time, since longer clamping seem to lead to higher IsoP levels [52], as well as the time point of sampling following reperfusion and the specimen analyzed, e.g. plasma, interstitial fluid, urine or tissue. Consistently to our observation of an increase of total $5(R, S)-5-\mathrm{F}_{2 \mathrm{t}}$-IsoP levels in the kidney $4 \mathrm{~h}$ after reperfusion and a decrease after $24 \mathrm{~h}$ (Fig. 4), in a rat model of unilateral IRI an increase of oxidized phosphatidylcholine species containing IsoP was observed $6 \mathrm{~h}$ after reperfusion which decreased after $24 \mathrm{~h}$ [53]. A similar time course of IsoP level was also observed in the liver of $\mathrm{CCl}_{4}$ treated rats (see above) [7]. These studies show that the time point of measuring oxidative damage for the evaluation of oxidative stress based on IsoP and likewise probably also epoxy-PUFA is crucial [54]. Interestingly, while showing the same time dependent trend, ARA and DHA derived $5(R, S)-5-\mathrm{F}_{2 \mathrm{t}}$-IsoP and $4(R, S)-4-\mathrm{F}_{4 \mathrm{t}}$-NeuroP, respectively, were modulated to a different extent in the time course of IRI in mice (Fig. 4). Also species specific differences might result in different time courses or extent of changes. Taken together, probably the ischemia reperfusion injury induced oxidative stress does not cause strong lipid oxidation in the investigated model and at the investigated time points. Therefore, other oxidative stress models, e.g. $\mathrm{CCl}_{4}$ induced liver toxicity $[8,9,55]$ or paraquat induced lung toxicity $[56,57]$ should be used to evaluate the biological significance of the modulated trans/ cis-epoxy-PUFA ratio during oxidative stress as seen for the $t$-BOOH induced oxidative stress models. 


\section{Conclusion}

Based on the presented results, we suggest a potential new biomarker of oxidative damage: the trans/cis-epoxy-PUFA ratio. In the investigated human cell lines from hepatic, colorectal and renal origin, as well as in the model organism C. elegans an increase in the trans/cisepoxy-PUFA ratio with $t$-BOOH induced oxidative stress was observed. The trans/cis-epoxy-PUFA ratio correlates perfectly with common marker of oxidative stress, i.e. IsoP. However, in the investigated in vivo model of murine renal ischemia reperfusion injury an effect on the trans/cis-epoxy-PUFA ratio was absent, underlining the need for further investigations especially regarding different oxidative stress agents with different modes of inducing oxidative stress to validate its suitability. This analysis could also pave the way to a mechanistically understanding of trans-epoxy-PUFA formation and understanding of their biological role.

\section{Acknowledgement}

Our work is supported by the Fonds der Chemischen Industrie (Grants to KR, JB and NHS) and the German Research Foundation (DFG, Grant SCHE 1801 to NHS and BO 4103/2-1 to JB). We would like to acknowledge the Caenorhabditis Genetics Center (CGC), which is funded by the NIH Office of Research Infrastructure Programs (P40 OD010440), for providing the N2 strain used in this manuscript.

\section{References}

[1] H. Sies, C. Berndt, D.P. Jones, Annu. Rev. Biochem. 86 (1) (2017) 715-748,

[2] D. Giustarini, I. Dalle-Donne, D. Tsikas, R. Rossi, Oxidative stress and human diseases: origin, link, measurement, mechanisms, and biomarkers, Crit. Rev. Clin. Lab. Sci. 46 (5-6) (2009) 241-281.

[3] L. Xu, T.A. Davis, N.A. Porter, Rate constants for peroxidation of polyunsaturated fatty acids and sterols in solution and in liposomes, J. Am. Chem. Soc. 131 (36) (2009) 13037-13044.

[4] H. Yin, L. Xu, N.A. Porter, Free radical lipid peroxidation: mechanisms and analysis, Chem. Rev. 111 (10) (2011) 5944-5972.

[5] J.D. Morrow, T.M. Harris, L.J. Roberts, 2nd, Noncyclooxygenase oxidative formation of a series of novel prostaglandins: analytical ramifications for measurement of eicosanoids, Anal. Biochem. 184 (1) (1990) 1-10.

[6] U. Jahn, J.M. Galano, T. Durand, Beyond prostaglandins-chemistry and biology of cyclic oxygenated metabolites formed by free-radical pathways from polyunsaturated fatty acids, Angew. Chemie 47 (32) (2008) 5894-5955.

[7] J.D. Morrow, J.A. Awad, H.J. Boss, I.A. Blair, L.J. Roberts, 2nd, Non-cycloox ygenase-derived prostanoids (F2-isoprostanes) are formed in situ on phospholipids, Proceedings of the National Academy of Sciences of the United States of America 89 (22) (1992) 10721-10725.

[8] J.D. Morrow, K.E. Hill, R.F. Burk, T.M. Nammour, K.F. Badr, L.J. Roberts, 2nd, A series of prostaglandin F2-like compounds are produced in vivo in humans by a non-cyclooxygenase, free radical-catalyzed mechanism, Proceedings of the National Academy of Sciences of the United States of America 87 (23) (1990) 9383-9387.

[9] M.B. Kadiiska, B.C. Gladen, D.D. Baird, D. Germolec, L.B. Graham, C.E. Parker, A. Nyska, J.T. Wachsman, B.N. Ames, S. Basu, N. Brot, G.A. Fitzgerald, R.A. Floyd, M. George, J.W. Heinecke, G.E. Hatch, K. Hensley, J.A. Lawson, L.J. Marnett, J.D. Morrow, D.M. Murray, J. Plastaras, L.J. Roberts 2nd, J. Rokach, M.K. Shigenaga, R.S. Sohal, J. Sun, R.R. Tice, D.H. Van Thiel, D. Wellner, P.B. Walter, K.B. Tomer, R.P. Mason, J.C. Barrett, Biomarkers of oxidative stress study II: are oxidation products of lipids, proteins, and DNA markers of CCl4 poisoning? Free Radic. Biol. Med. 38 (6) (2005) 698-710.

[10] G.L. Milne, Q. Dai, L.J. Roberts, 2nd, the isoprostanes-25 years later, Biochim. Biophys. Acta 1851 (4) (2015) 433-445.

[11] T.J. Van't erve, M.B. Kadiiska, S.J. London, R.P. Mason, Classifying oxidative stress by F2-isoprostane levels across human diseases: a meta-analysis, Redox Biol. 12 (2017) 582-599.

[12] M. Hecker, V. Ullrich, C. Fischer, C.O. Meese, Identification of novel arachidonic acid metabolites formed by prostaglandin H synthase, Eur. J. Biochem. 169 (1) (1987) 113-123.

[13] T. Klein, F. Reutter, H. Schweer, H.W. Seyberth, R.M. Nüsing, Generation of the isoprostane 8-Epi-prostaglandin $\mathrm{F}_{2 \alpha}$ in Vitro and in vivo via the cyclooxygenases, $\mathrm{J}$.
Pharmacol. Exp. Ther. 282 (3) (1997) 1658-1665.

[14] T.J.van't Erve, F.B. Lih, M.B. Kadiiska, L.J. Deterding, T.E. Eling, R.P. Mason, Reinterpreting the best biomarker of oxidative stress: the 8 -iso-PGF2 $\alpha /$ PGF2 $\alpha$ ratio distinguishes chemical from enzymatic lipid peroxidation, Free Radic. Biol. Med. 83 (2015) 245-251.

[15] T.J. van't Erve, F.B. Lih, C. Jelsema, L.J. Deterding, T.E. Eling, R.P. Mason, M.B. Kadiiska, Reinterpreting the best biomarker of oxidative stress: the 8-isoprostaglandin F2 $\alpha$ /prostaglandin F2 $\alpha$ ratio shows complex origins of lipid peroxidation biomarkers in animal models, Free Radic. Biol. Med. 95 (2016) 65-73.

[16] C. Morisseau, B.D. Hammock, Impact of soluble epoxide hydrolase and epoxyeicosanoids on human health, Annu. Rev. Pharmacol. Toxicol. 53 (1) (2013) 37-58.

[17] A. Konkel, W.-H. Schunck, Role of cytochrome P450 enzymes in the bioactivation of polyunsaturated fatty acids, Biochimica et Biophysica Acta (BBA) - Proteins and Proteomics 1814 (1) (2011) 210-222.

[18] C. Westphal, A. Konkel, W.-H. Schunck, Cytochrome P450 enzymes in the bioactivation of polyunsaturated fatty acids and their role in cardiovascular disease, in: E.G. Hrycay, S.M. Bandiera (Eds.), Monooxygenase, Peroxidase and Peroxygenase Properties and Mechanisms of Cytochrome P450, Springer International Publishing, Cham, 2015, pp. 151-187.

[19] J.H. Capdevila, J.R. Falck, R.C. Harris, Cytochrome P450 and arachidonic acid bioactivation, Molecular and functional properties of the arachidonate monooxygenase, Journal of lipid research 41 (2) (2000) 163-181.

[20] J.H. Capdevila, A. Karara, D.J. Waxman, M.V. Martin, J.R. Falck, F.P. Guenguerich, Cytochrome P-450 enzyme-specific control of the regio- and enantiofacial selectivity of the microsomal arachidonic acid epoxygenase, J. Biol. Chem. 265 (19) (1990) 10865-10871.

[21] I. Willenberg, A.I. Ostermann, N.H. Schebb, Targeted metabolomics of the arachidonic acid cascade: current state and challenges of LC-MS analysis of oxylipins, Anal. Bioanal. Chem. 407 (10) (2015) 2675-2683.

[22] K. Bernstrom, K. Kayganich, R.C. Murphy, F.A. Fitzpatrick, Incorporation and distribution of epoxyeicosatrienoic acids into cellular phospholipids, J. Biol. Chem. 267 (6) (1992) 3686-3690.

[23] H. Jiang, J.C. McGiff, J. Quilley, D. Sacerdoti, L.M. Reddy, J.R. Falck, F. Zhang, K.M. Lerea, P.Y. Wong, Identification of 5,6-trans-epoxyeicosatrienoic acid in the phospholipids of red blood cells, J. Biol. Chem. 279 (35) (2004) 36412-36418.

[24] T. Aliwarga, B.S. Raccor, R.N. Lemaitre, N. Sotoodehnia, S.A. Gharib, L. Xu, R.A. Totah, Enzymatic and free radical formation of cis- and trans- epoxyeicosatrienoic acids in vitro and in vivo, Free Radic. Biol. Med. 112 (2017) 131-140.

[25] T. Nakamura, D.L. Bratton, R.C. Murphy, Analysis of epoxyeicosatrienoic and monohydroxyeicosatetraenoic acids esterified to phospholipids in human red blood cells by electrospray tandem mass spectrometry, J. Mass Spectrom. 32 (8) (1997) 888-896.

[26] H. Jiang, J. Quilley, L.M. Reddy, J.R. Falck, P.Y. Wong, J.C. McGiff, Red blood cells: reservoirs of cis- and trans-epoxyeicosatrienoic acids, Prostaglandins Other Lipid Mediat. 75 (1-4) (2005) 65-78.

[27] K.M. Rund, A.I. Ostermann, L. Kutzner, J.-M. Galano, C. Oger, C. Vigor, S. Wecklein, N. Seiwert, T. Durand, N.H. Schebb, Development of an LC-ESI(-)-MS/MS method for the simultaneous quantification of 35 isoprostanes and isofurans derived from the major n3- and n6-PUFAs, Anal. Chim. Acta 1037 (2018) 63-74.

[28] C. Oger, Y. Brinkmann, S. Bouazzaoui, T. Durand, J.M. Galano, Stereocontrolled access to isoprostanes via a bicyclo[3.3.0] octene framework, Org. Lett. 10 (21) (2008) 5087-5090.

[29] C. Cuyamendous, K.S. Leung, T. Durand, J.C. Lee, C. Oger, J.M. Galano, Synthesis and discovery of phytofurans: metabolites of alpha-linolenic acid peroxidation, Chem. Commun. 51 (86) (2015) 15696-15699.

[30] A. de la Torre, Y.Y. Lee, A. Mazzoni, A. Guy, V. Bultel-Poncé, T. Durand, C. Oger, J.C.-Y. Lee, J.-M. Galano, Total syntheses and in vivo quantitation of novel neurofuran and dihomo-isofuran derived from docosahexaenoic acid and adrenic acid, Chem. Eur. J. 21 (6) (2015) 2442-2446.

[31] C. Oger, V. Bultel-Poncé, A. Guy, T. Durand, J.-M. Galano, Total synthesis of isoprostanes derived from adrenic acid and EPA, European J. Org. Chem. 13 (2012) (2012) 2621-2634.

[32] A. Guy, C. Oger, J. Heppekausen, C. Signorini, C. De Felice, A. Fürstner, T. Durand, J.-M. Galano, Oxygenated metabolites of n-3 polyunsaturated fatty acids as potential oxidative stress biomarkers: total synthesis of 8-F3t-IsoP, 10-F4t-NeuroP and [D4]-10-F4t-NeuroP, Chem. Eur. J. 20 (21) (2014) 6374-6380.

[33] M. Mimmler, S. Peter, A. Kraus, S. Stroh, T. Nikolova, N. Seiwert, S. Hasselwander, C. Neitzel, J. Haub, B.H. Monien, P. Nicken, P. Steinberg, J.W. Shay, B. Kaina, J. Fahrer, DNA damage response curtails detrimental replication stress and chromosomal instability induced by the dietary carcinogen PhIP, Nucleic Acids Res. 44 (21) (2016) 10259-10276.

[34] S. Brenner, The genetics of Caenorhabditis elegans, Genetics 77 (1) (1974) 71-94.

[35] A. Thorenz, K. Derlin, C. Schröder, L. Dressler, V. Vijayan, P. Pradhan, S. Immenschuh, A. Jörns, F. Echtermeyer, C. Herzog, R. Chen, S. Rong, J.H. Bräsen, C. van Kooten, T. Kirsch, C. Klemann, M. Meier, A. Klos, H. Haller, B. Hensen, F. Gueler, Enhanced activation of interleukin-10, heme oxygenase-1, and AKT in C5aR2-deficient mice is associated with protection from ischemia reperfusion injury-induced inflammation and fibrosis, Kidney Int. 94 (4) (2018) 741-755.

[36] A.I. Ostermann, I. Willenberg, N.H. Schebb, Comparison of sample preparation methods for the quantitative analysis of eicosanoids and other oxylipins in plasma by means of LC-MS/MS, Anal. Bioanal. Chem. 407 (5) (2015) 1403-1414.

[37] S.H. Hwang, H.-J. Tsai, J.-Y. Liu, C. Morisseau, B.D. Hammock, Orally Bioavailable Potent Soluble Epoxide Hydrolase Inhibitors, J. Med. Chem. 50 (16) (2007) 3825-3840.

[38] C.F. Labuschagne, N.J. van den Broek, P. Postma, R. Berger, A.B. Brenkman, A 
protocol for quantifying lipid peroxidation in cellular systems by F2-isoprostane analysis, PLoS One 8 (11) (2013) e80935.

[39] C.F. Labuschagne, E.C. Stigter, M.M. Hendriks, R. Berger, J. Rokach,

H.C. Korswagen, A.B. Brenkman, Quantification of in vivo oxidative damage in Caenorhabditis elegans during aging by endogenous F3-isoprostane measurement, Aging Cell 12 (2) (2013) 214-223.

[40] M. Hattori, H. Arai, K. Inoue, Purification and characterization of bovine brain platelet-activating factor acetylhydrolase, J. Biol. Chem. 268 (25) (1993) 18748-18753.

[41] T.M. McIntyre, S.M. Prescott, D.M. Stafforini, The emerging roles of PAF acetylhydrolase, J. Lipid Res. 50 (Supplement) (2009) S255-S259.

[42] D.M. Stafforini, J.R. Sheller, T.S. Blackwell, A. Sapirstein, F.E. Yull, T.M. McIntyre, J.V. Bonventre, S.M. Prescott, L.J. Roberts, Release of free F2-isoprostanes from esterified phospholipids is catalyzed by intracellular and plasma platelet-activating factor acetylhydrolases, J. Biol. Chem. 281 (8) (2006) 4616-4623.

[43] A. Matsuzawa, K. Hattori, J. Aoki, H. Arai, K. Inoue, Protection against oxidative stress-induced cell death by intracellular platelet-activating factor-acetylhydrolase II, J. Biol. Chem. 272 (51) (1997) 32315-32320.

[44] H. Yin, J.D. Brooks, L. Gao, N.A. Porter, J.D. Morrow, Identification of novel autoxidation products of the $\omega-3$ fatty acid eicosapentaenoic acid in vitro and in vivo, J. Biol. Chem. 282 (41) (2007) 29890-29901.

[45] H. Yin, E.S. Musiek, L. Gao, N.A. Porter, J.D. Morrow, Regiochemistry of neuroprostanes generated from the peroxidation of docosahexaenoic acid in vitro and in vivo, J. Biol. Chem. 280 (28) (2005) 26600-26611.

[46] D.O. Stene, R.C. Murphy, Metabolism of leukotriene E4 in isolated rat hepatocytes, Identification of beta-oxidation products of sulfidopeptide leukotrienes, The Journal of biological chemistry 263 (6) (1988) 2773-2778.

[47] J.A. Lawson, S. Kim, W.S. Powell, G.A. FitzGerald, J. Rokach, Oxidized derivatives of $\omega-3$ fatty acids: identification of IPF3 $\alpha$-VI in human urine, J. Lipid Res. 47 (11)
(2006) 2515-2524.

[48] J.L. Watts, J. Browse, Genetic dissection of polyunsaturated fatty acid synthesis in Caenorhabditis elegans, Proc. Natl. Acad. Sci. 99 (9) (2002) 5854-5859.

[49] D. Fulton, J.R. Falck, J.C. McGiff, M.A. Carroll, J. Quilley, A method for the determination of 5,6-EET using the lactone as an intermediate in the formation of the diol, J. Lipid Res. 39 (8) (1998) 1713-1721.

[50] D.N. Granger, P.R. Kvietys, Reperfusion injury and reactive oxygen species: the evolution of a concept, Redox Biol. 6 (2015) 524-551.

[51] M. Kadkhodaee, G.R. Hanson, R.A. Towner, Z.H. Endre, Detection of hydroxyl and carbon-centred radicals by EPR spectroscopy after ischaemia and reperfusion of the rat kidney, Free Radic. Res. 25 (1) (1996) 31-42.

[52] Z. Wang, J.L. Colli, C. Keel, K. Bailey, L. Grossman, D. Majid, B.R. Lee, Quantitation of renal ischemia and reperfusion injury after renal artery clamping in an animal model, J. Endourol. 26 (1) (2012) 21-25.

[53] Z. Solati, A.L. Edel, Y. Shang, K.O.A. Ravandi, Oxidized phosphatidylcholines are produced in renal ischemia reperfusion injury, PLoS One 13 (4) (2018) e0195172.

[54] B. Halliwell, C.Y. Lee, Using isoprostanes as biomarkers of oxidative stress: some rarely considered issues, Antioxid. Redox Signal. 13 (2) (2010) 145-156.

[55] E. Albano, K.A. Lott, T.F. Slater, A. Stier, M.C. Symons, A. Tomasi, Spin-trapping studies on the free-radical products formed by metabolic activation of carbon tetrachloride in rat liver microsomal fractions isolated hepatocytes and in vivo in the rat, Biochem. J. 204 (2) (1982) 593-603.

[56] R.J. Dinis-Oliveira, J.A. Duarte, A. Sánchez-Navarro, F. Remião, M.L. Bastos, F. Carvalho, Paraquat poisonings: mechanisms of lung toxicity, clinical features, and treatment, Crit. Rev. Toxicol. 38 (1) (2008) 13-71.

[57] F.E. Harrison, J.L. Best, M.E. Meredith, C.R. Gamlin, D.-B. Borza, J.M. May, Increased expression of SVCT2 in a new mouse model raises ascorbic acid in tissues and protects against paraquat-induced oxidative damage in lung, PLoS One 7 (4) (2012) e35623. 